\title{
How can landscape ecology contribute to sustainability science?
}

\author{
Paul Opdam • Sandra Luque · Joan Nassauer $\cdot$ Peter H. Verburg • \\ Jianguo Wu
}

Received: 7 January 2018/ Accepted: 9 January 2018/Published online: 15 January 2018

(C) Springer Science+Business Media B.V., part of Springer Nature 2018
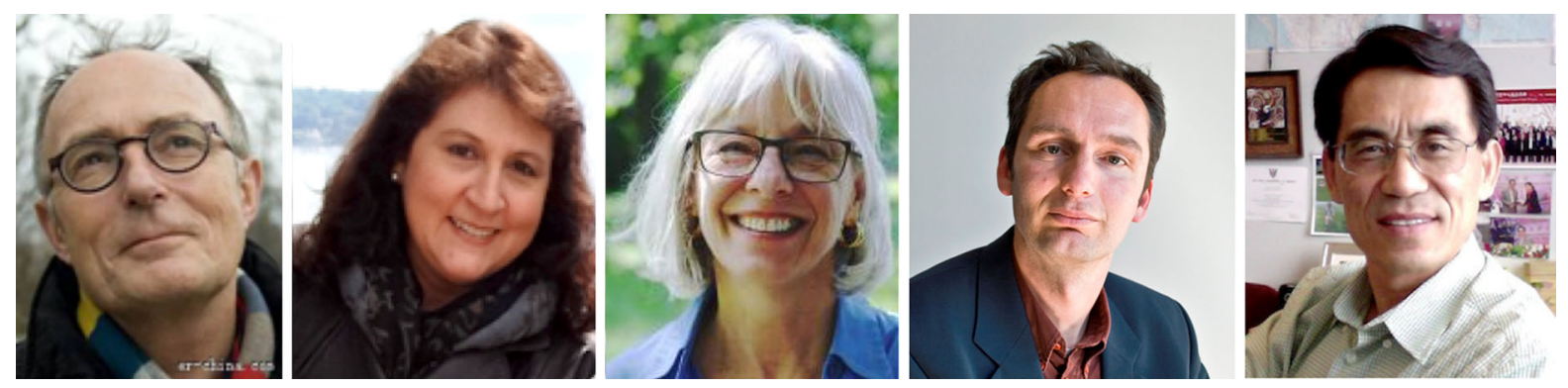

While landscape ecology is distinct from sustainability science, landscape ecologists have expressed their ambitions to help society advance sustainability of landscapes. In this context Wu (2013) coined the concept of landscape sustainability science. In August of 2017 we joined the 5th forum of landscape sustainability science in

P. Opdam ( $($ )

Land Use Planning Group \& Alterra, Wageningen University and Research, Wageningen, The Netherlands e-mail: paul.opdam@wur.nl

\section{S. Luque}

IRSTEA - UMR TETIS Territoires, Environnement, Télédétection ET Information Spatiale, Montpellier, France

\section{J. Nassauer}

School for Environment and Sustainability, University of Michigan, Ann Arbor, USA

\section{P. H. Verburg}

Institute for Environmental Studies, Vrije Universiteit

Amsterdam, Amsterdam, The Netherlands

\section{P. H. Verburg}

Swiss Federal Institute for Forest, Snow and Landscape Research (WSL), Birmensdorf, Switzerland

\section{J. $\mathrm{Wu}$}

School of Life Sciences, School of Sustainability, Julie A. Wrigley Global Institute of Sustainability, Arizona State University, Tempe, USA

J. Wu

Center for Human-Environment System Sustainability (CHESS), Beijing Normal University, Beijing, China 
Beijing (see http://leml.asu.edu/chess/FLSS/05/index.html). To inspire landscape ecologists in developing research for a more sustainable future, we highlight some of the key points raised there. We emphasize challenges that have been identified in sustainability science that we consider particularly relevant for landscape sustainability. Then we describe how landscape ecology could enrich sustainability science. Finally, we propose five topics for landscape ecology research to advance landscape sustainability science.

\section{Key challenges in sustainability science}

Reflective papers on the progress in sustainability research have produced important insights in key features and enabling factors that determine how science may contribute to transitions towards sustainability (Lang et al. 2012; Miller 2013; Miller et al. 2014; Fischer et al. 2015; Balvanera et al. 2017 and Schäpke et al. 2017). For landscape ecologists, we think the following four insights are of particular relevance.

Research alone cannot determine whether a particular landscape is in a sustainable state

A sustainable landscape is a normative concept. It recognizes that landscape functions are the foundation for solutions to problems of human well-being ( $\mathrm{Wu}$ 2013). However, this may mean different things to different stakeholders. The identification of problems and solutions is inevitably connected to beliefs, values and preferences of people who live in the landscape, as well as others who depend on its resources and functions. Therefore, science can identify a sustainable landscape only in dialogue with these stakeholders. This dialogue is a fundamental connection between scientific knowledge and human experiences in local landscapes (Miller 2013), and should allow for choices about the future landscape to be expressed by mixed groups of stakeholders (including policy makers). For example, in a modelling approach with socioeconomic scenarios that facilitates building a vision about a future landscape, scientists should select indicators for sustainability in dialogue with stakeholders and determine with them which are the required levels of those indicators to meet the sustainability aims of local society. Scientists could bring in the concept of natural capital and determine in dialogue what level of natural capital is critical for maintaining the capacity of the landscape to provide long-term landscape benefits to future generations. In this dialogue the concepts of weak and strong sustainability (Ekins et al. 2003; Wu 2013) may be used to deepen understanding of what a sustainable landscape may be.

Changes to make local landscapes more sustainable have implications for landscapes elsewhere

Although we argue that landscape sustainability is framed in the context of local or regional landscapes, any decision to adapt the use of a local landscape may have consequences for the sustainability of landscapes elsewhere in the world (Meyfroidt et al. 2013). For example, lowering the intensity of food production in one area may trigger an increase of land use intensity elsewhere. Another example is that the whole global population benefits from climate mitigation capacities of forested landscapes in a region. Therefore, science should give insight about how local, regional, and global drivers and effects are connected (Verburg et al. 2015) so that local decision makers are aware of the implications of their own choices for the sustainability of the 'system earth'.

Solutions-oriented research receives inadequate attention in science

By definition, sustainability hinges on the dynamic relationship between society and nature. This relationship can be taken as a basis for analytical and integrative research for understanding complex social-ecological systems (SES). As Miller et al. (2014) and Fischer et al. (2015) have pointed out, SES has been the dominant focus of sustainability science thus far. However, generating landscape solutions has been less widely pursued within sustainability science-despite it being defined as a place-based, use-inspired science (Kates 2012). Therefore, solutions-oriented research must now be a priority (Miller et al. 2014; Fischer et al. 2015). Generating sustainable landscape solutions requires societal engagement, collaboration between sectors and creativity in seeking new landscape patterns to 
make sure that solutions are embedded in society (Nassauer and Opdam 2008; Musacchio 2011). Hence, collaborative and participatory (transdisciplinary) research aimed at creating solutions is essential (Lang et al. 2012; Wang et al. 2014).

Science can facilitate societal transformations towards sustainability

Moving landscapes toward sustainability often requires fundamental societal transformations (also called transitions, see Kates and Parris 2003; Lambin 2005; Loorbach 2010), including changes in how landscapes are valued, newly established relations between societal actors, and new governance approaches. Landscape research in design/planning, social, and environmental disciplines are needed to understand how to promote, trigger, and facilitate such transitions. Increasing evidence suggests that collaborative forms of governance, which are adaptive and iterative (rather than rule-based and linear,) support such transformations (Armitage et al. 2009). Such governance requires knowledge exchange and complex forms of learning in social networks (Pahl-Wostl 2009). Where collaborative forms of governance emerge, an effective dialogue between science and practice requires that scientists go beyond providing information. Rather, science must engage with society in a way that fosters both motivation and capacity for societal change (Lambin 2005; Schäpke et al. 2017).

\section{What landscape ecology has to offer to sustainability science}

Since landscape ecology envisions the landscape as the outcome of the complex relations between humans and nature, it provides a useful framework for sustainability science. The call for interdisciplinary, multiple purpose and multiple scale approaches in landscape ecology is consistent with the Sustainable Development Goals identified by the UN 2030 Agenda for Sustainable Development. To become more effective in generating sustainable landscape solutions, landscape ecology should integrate ecological and social mechanisms into system thinking. Concepts such as social-ecological networks and nexus thinking (Biggs et al. 2015; Fürst et al. 2017) could be further developed by landscape ecologists as a basis for spatially explicit analytical and design approaches. In the following we propose four fundamental landscape ecological contributions to sustainability science.

A spatially explicit approach

Miller et al. (2014) identified the need for sustainability science to pay more attention to mapping sustainability values. Mapping spatial patterns is a core method of landscape ecology. Mapping approaches are equally essential for sustainability research and practice because, after all, the sustainability of a place is determined not only by what it is composed of, but also how its components are spatially arranged and managed. Landscape ecology brings spatial extent, spatial heterogeneity and spatial connectivity into the fore. The challenge is to link these spatial characteristics to values that are meaningful to landscape decision makers, including residents, land owners and practitioners. Spatial pattern has been associated with the performance of natural processes to produce benefits to human society. For example, numerous studies have shown that the form and configuration of landscapes affect the psychological and physical wellbeing of humans, including all biodiversity-based landscape services. Dronova (2017) highlighted the potential of landscape heterogeneity to link multiple landscape benefits. Such a link between pattern and value is of great relevance in building multi-functional visions and in designing future landscapes (Termorshuizen and Opdam 2009).

A multiple scale approach

While many landscape decisions are made at a local level, the drivers behind these decisions are often fuelled by economic processes resulting from decisions and behaviours at spatial scale levels far above the landscape level. In contrast, when decisions based on sustainability principles are made about local landscapes, the results may not be sustainable from a global perspective. Multi-scale interactions have been long addressed by landscape ecology, and now, there is a great need to connect cross scale ecological interactions with social and economic values as well as with governance systems across multiple scales (Padt et al. 2014; Nash et al. 2014). 
A system concept that invites stakeholders and disciplines to share their knowledge, values, and concerns

Landscape ecology offers sustainability science a tangible system concept, the landscape, that can be seen, perceived, enjoyed, and measured. Because of its tangibility, landscape can be a common platform, for different disciplines and sectors to work together to find common sustainable solutions (Nassauer 2012). This characteristic allows people with different worldviews and backgrounds to discover their possible shared interests in the functions embodied by landscapes. Landscape as well as landscape services have been reported to play the role of boundary object in collaborative planning and design processes: they bind people, stimulate collaboration and offer a discursive space for debate (Opdam et al. 2015, Westerink et al. 2017).

A systems approach that connects social and ecological science for sustainable solutions

Creating sustainable solutions requires the interchange of social and ecological scientific disciplines to create an interdisciplinary approach. A recent review on the so-called landscape approach (Arts et al. 2017) illustrates the many and widely different scientific views on the landscape. From a scientific perspective, it may be inspiring to have so many opportunities for scientific debate. But for the creation of on-the-ground solutions in real-world landscapes, divergent views may not always be helpful. Landscape ecology can offer a design approach based on landscape acting as boundary object. As Nassauer and Opdam (2008) put it: "design [should] be adopted as a boundary concept between science and practice, and further, we assert that landscape ecology should be at the active edge of this boundary". Creating value in the landscape in a way that works long-term requires understanding of how physical patterns can be adapted in such a way that what society needs from hydrological, geomorphological and ecological processes and what society values in the experience of landscapes can be embodied in the same places.

\section{Five research challenges for landscape ecologists}

Building on the points in the previous section, we propose five research themes for landscape ecology to improve its contribution to sustainability science. We illustrate each point with some recent examples from the literature.

Integrating ecological and social mechanisms

Systems thinking is important to provide a conceptual basis for both analytical and design approaches in landscape ecology. For being relevant to sustainability, landscape ecological and socio-economic theories should be merged to create spatially explicit systems approaches. The concept of social-ecological systems can be a good starting point because it connects ecological and social systems by two feedbacks: the perception within the community of benefits from landscapes and, secondly, the interventions in the landscape that are taken to ensure better value out of these benefits. However, considering the spatial organization of landscapes, social-ecological systems thinking will become more salient for landscape sustainability if the interdependence of the spatial structure of social and ecological components is explicitly recognized. Therefore, the recent progress in social-ecological network thinking (Janssen et al. 2006; Bodin et al. 2016) offers interesting opportunities for further exploration in landscape ecology. Network thinking sees patches and actors within the landscape as nodes and the interactions between nodes as links. Network analysis methods have long been practiced in social science, and more recently applied in ecology and natural resource governance (e.g. Romolini et al. 2016). Interesting opportunities for social-ecological analysis can be found in the analysis of data from social media. For example, geo-tagged landscape photographs taken from social media networks were analysed to reveal the intertwined relation between cultural values and individuals perceptions of the landscape (Tenerelli et al. 2017).

Connecting landscape ecology to governance science

Landscape governance as a concept was coined by Görg in 2007. There is extensive literature suggesting that creating sustainable landscapes is more successful 
when local communities feel ownership in their future environment. Collaborative and participatory approaches allow a better use of local knowledge, more effective social learning and more responsibility during implementation. Several types of collaborative forms of landscape governance have been proposed. One specification of landscape governance, coined as the landscape approach, emerged outside landscape ecology in association with integrated land management (Sayer 2009, see for a recent review from a social perspective Arts et al. 2017). Another one, landscape stewardship, is a type of collaborative landscape governance recently defined and explored in a book edited by Bieling and Plieninger (2017). These research lines offer opportunities for landscape ecologists to connect pattern-process related approaches with landscape governance. For example, Opdam et al. (2016) proposed that information about the common benefits of landscapes and about the interdependence of land owners in a landscape area to create these benefits would facilitate collaborative landscape governance, and reviewed the evidence in literature for this hypothesis.

\section{Linking scale levels in decision making}

Effective landscape stewardship requires people to care for a place in a way that pays attention to local resources (Nassauer 2011). How can local communities that decide about landscape adaptation for more sustainability recognize the implications for sustainability at global and regional scale levels? There is a need to engage stakeholders in novel ways that convey how a local landscape and its inhabitants are part of global phenomena that affect their own landscape and are affected by the landscape. Accounting for this in bottom-up approaches is a big challenge, but should be complemented by action at levels beyond the local landscape, that are critical in steering the landscapes future. It is exactly the multi-scale thinking that has such a long tradition in landscape ecology that can link up with multi-level governance approaches to help move forward on this aspect. Cumming et al. (2013) concluded that "one of the central problems of landscape sustainability is that of aligning the scale of demand for ecosystem services with the scale at which ecosystem service can be sustainably provided". Focusing on landscape care as a driver, Nassauer and colleagues examined how the scales of production and demand for exurban housing could be linked to carbon storage (Currie et al. 2016). Solving this problem in any particular area requires a further exploration of what a sustainable provision of a demanded landscape service could mean in the local context, and what it would require in terms of landscape pattern at appropriate scales. Answering such questions together with local actors will also be a challenge to social learning capacities and collaborative action.

Incorporate design in landscape ecology to create solutions

Sustainability needs landscape analytical approaches to explore problems and make assessments of policy, but as such these approaches will never provide solutions. Innovations emerge in landscape design processes at many scales. Building on the pattern: process: design paradigm for landscape ecology (Nassauer and Opdam 2008), landscape ecology should more fully embrace landscape as a powerful medium for innovation (Nassauer 2012). Employing landscape as the medium for transdisciplinary experimentation about sustainability solutions should be integral to both landscape ecology and sustainability science. To effect more sustainable landscapes, a broad definition of design, including vernacular and engineering solutions, is required to address landscape sustainability. In its broadest sense, design incorporates activities of governance, planning, and maintenance. This definition opens the way for landscape ecology to incorporate design sciences and social sciences to contribute to sustainable landscape solutions.

Design has also been conceptualized in a somewhat narrower meaning as the creative step in a joined learning cycle that includes understanding, exploration, design and transformation (Bürgi et al. 2017). Steingröver et al. (2010) reported how they facilitated a group of farmers and other stakeholders through a joined learning and design process aimed at creating a green infrastructure for the provision of landscape services. The design of sustainable solutions requires understanding how societal values of landscapes depends on physical patterns through landscape functioning (Termorshuizen and Opdam 2009). If such information is used in design approaches it needs to be 
connected to the dominant cultural values for the appearance of landscapes.

Bridging the gap between science and practice

Over the years, landscape ecologists have reflected on the gap between science and practice (e.g., Opdam et al. 2013). Often the suggested improvements were limited to the need of better communication and connecting to policy makers. Here we propose that a better understanding of how scientific information interacts with social processes is fundamental to bridging the gap between science and practice. This is a topic that requires theory building and empirical research in the interface between landscape ecology and social sciences, and progress is essential for science to be more effective in contributing to sustainable landscape solutions. Interesting contributions to this theory building haven been published and should be integrated in landscape ecological thinking. Cash et al. (2003) suggested credibility, saliency, and legitimacy of scientific information as the three key features that determine use by practitioners and decision makers. Raquez and Lambin (2006) addressed how scientific information could impact social-ecological transformation towards sustainability. Based on 46 case studies, they identified three key factors associated with success in achieving a more sustainable land use practice: (1) information about the need and possibility to change, (2) capacity of the society to organize change, and (3) motivation (willingness) of society to change. Scientific information and activities should contribute to these three factors. Opdam et al. (2016) recently reviewed a number of studies on the interface between landscape ecology and social sciences, and found that multifunctional concepts like green infrastructure and landscape services can facilitate actors from different sectors to converge towards a common goal and also stimulate collaborative landscape management. The role of landscapes and landscape services as boundary objects (as mentioned before) is of relevance here as well.

\section{Conclusion}

We see landscape sustainability science as an interface between landscape ecology and sustainability science. This interface has to be developed in order to make landscape ecological research more effective in contributing transformations towards a more sustainable future. We have identified five key research challenges that particularly need more attention in landscape sustainability research. We want to emphasize that addressing these challenges and the associated landscape ecological questions requires connecting to other domains of environmental sciences, including design science, social science, and governance science. Achieving global sustainability demands a fundamental change of the way humans interact with nature in the landscape. This poses a huge challenge to mankind. For science to play a major role in this transformation, landscape ecologists have to leave their comfort zone and explore joined efforts with colleagues of other disciplines. It is at this interface of science domains that innovations takes place; it is here that old paradigms are revised or replaced by new ones and that new solutions are born. The world needs landscape ecology to become more holistic and humanistic, in order to be more effective in creating solutions for a more sustainable society.

\section{References}

Armitage DR, Plummer R, Berkes F et al (2009) Adaptive comanagement for social-ecological complexity. Front Ecol Environ 7:95-102

Arts B, Buizer M, Horlings I et al (2017) Landscape approaches: a state-of-the-art-review. Annu Rev Environ Resour 42:439-463

Balvanera P, Daw TM, Gardner T et al (2017) Key features for more successful place-based sustainability research on social-ecological systems: a Programme on Ecosystem Change and Society (PECS) perspective. Ecol Soc 22(1):14. https://doi.org/10.5751/ES-08826-220114

Bieling C, Plieninger T (eds) (2017) The science and practice of landscape Stewardship. Cambridge University Press, Cambridge, p 388

Biggs EM, Bruce E, Boruff B et al (2015) Sustainable development and the water-energy-food nexus: a perspective on livelihoods. Environ Sci Policy 54:389-397

Bodin Ö, Robins G, McAllister RRJ et al (2016) Theorizing benefits and constraints in collaborative environmental governance: a transdisciplinary social-ecological network approach for empirical investigations. Ecol Soc 21(1):40. https://doi.org/10.5751/ES-08368-210140

Bürgi M, Ali P, Chowdhury A et al (2017) Integrated landscape approach: closing the gap between theory and application. Sustainability 9:1371. https://doi.org/10.3390/su9081371

Cash DW, Clark WC, Alcock F et al (2003) Knowledge systems for sustainable environment. PNAS 100:8086-8091 
Cumming GS, Olsson P, Chapin FS, Holling CS (2013) Resilience, experimentation, and scale mismatches in socialecological landscapes. Landscape Ecol 28:1139-1150

Currie WS, Kiger S, Nassauer JI et al (2016) Multi-scale heterogeneity in vegetation and soil carbon in exurban residential land of southeastern Michigan. Ecol Appl 26:1421-1436

Dronova I (2017) Environmental heterogeneity as a bridge between ecosystem service and visual quality objectives in management, planning and design. Landsc Urban Plan 163:90-106

Ekins P, Simon S, Deutsch L, Folke C, De Groot R (2003) A framework for the practical application of the concepts of critical natural capital and strong sustainability. Ecol Econ 44:165-185

Fischer J, Gardner TA, Bennett EM et al (2015) Advancing sustainability through mainstreaming a social-ecological systems perspective. Curr Opin Environ Sustain 14:144-149

Fürst C, Luque S, Geneletti D (2017) Nexus thinking-how ecosystem services (ES) can contribute to enhance the cross-scale and cross-sectoral coherence between land use, spatial planning and policy making. Int $\mathrm{J}$ Biodivers Sci Ecosyst Serv Manag 13:412-421

Görg C (2007) Landscape governance: the 'politics of scale' and the 'natural' conditions of places. Geoforum 38:954-966

Janssen MA, Bodin Ö, Anderies JM (2006) Toward a network perspective of the study of resilience in social-ecological systems. Ecol Soc 11(1):15

Kates RW (2012) From the unity of nature to sustainability science: ideas and practice. In: Weinstein MP, Turner RE (eds) Sustainability science: the emerging paradigm and the urban environment. Springer, Dordrecht, pp 3-19

Kates RW, Parris TM (2003) Long-term trends and a sustainability transition. Proc Natl Acad Sci (USA) 100:8062-8067

Lambin EF (2005) Conditions for sustainability of human-environmental systems: information, motivation, and capacity. Glob Environ Chang 15:177-180

Lang DJ, Wiek A, Bergmann M et al (2012) Transdisciplinary research in sustainability science: practices, principles, and challenges. Sustain Sci 7(supplement):25-43

Loorbach D (2010) Transition management for sustainable development: a prescriptive, complexity-based governance framework. Governance 23:161-183

Meyfroidt P, Lambin EF, Erb KH, Hertel TW (2013) Globalization of land use: distant drivers of land change and geographic displacement of land use. Curr Opin Environ Sustain 5:438-444

Miller TR (2013) Constructing sustainability Science: emerging perspectives and research trajectories. Sustain Sci 8:279-293

Miller TR, Wiek A, Sarewitz D et al (2014) The future of sustainability science: a solutions-oriented research agenda. Sustain Sci 9:239-246

Musacchio LR (2011) The grand challenge to operationalize landscape sustainability and the design-in-science paradigm. Landscape Ecol 26:1-5

Nash KL, Allen CR, Angeler DG et al (2014) Discontinuities, cross-scale patterns, and the organization of ecosystems. Ecology 95:654-667
Nassauer JI (2011) Care and stewardship: from home to planet. Landsc Urban Plan 100:321-323

Nassauer JI (2012) Landscape as medium and method for synthesis in urban ecological design. Landsc Urban Plan 106:221-229

Nassauer J, Opdam P (2008) Design in science: extending the landscape ecology paradigm. Landscape Ecol 23:633-644

Opdam P, Coninx I, Dewulf A, Steingrover E, Vos C, Van der Wal M (2016) Does information on landscape benefits influence collective action in landscape governance? Curr Opin Environ Sustain 18:107-114

Opdam P, Nassauer J, Wang Z et al (2013) Science for action at the local landscape scale. Landscape Ecol 28:1439-1445

Opdam P, Westerink J, Vos C, De Vries B (2015) The role and Evolution of Boundary concepts in transdisciplinary landscape planning. Plan Theor Pract 16:63-78

Padt F, Opdam P, Polman N, Termeer C (eds) (2014) Scalesensitive governance of the environment. Wiley, Chichester, p 321

Pahl-Wostl C (2009) A conceptual framework for analysing adaptive capacity and multi-level learning processes in resource governance regimes. Glob Environ Chang 19:354-365

Raquez P, Lambin EF (2006) Conditions for sustainable land use: case study evidence. J Land Use Sci 1:109-125

Romolini M, Bixler RP, Grove JM (2016) A social-ecological framework for urban stewardship network research to promote sustainable and resilient cities. Sustainability 8:956. https://doi.org/10.3390/su8090956

Sayer J (2009) Reconciling conservation and development: are landscapes the answer? Biotropica 41:649-652

Schäpke N, Omann I, Wittmayer JM, van Steenbergen F, Mock M (2017) Linking transitions to sustainability: a study of the societal effects of transition management. Sustainability 9:737. https://doi.org/10.3390/su9050737

Steingröver EG, Geertsema W, Van Wingerden WKRE (2010) Designing agricultural landscapes for natural pest control: a transdisciplinary approach in the Hoeksche Waard (The Netherlands). Landscape Ecol 25:825-838

Tenerelli P, Püffel C, Luque S (2017) Spatial assessment of aesthetic services in a complex mountain region: combining visual landscape properties with crowdsourced geographic information. Landscape Ecol 32:1097-1115

Termorshuizen J, Opdam P (2009) Landscape services as a bridge between landscape ecology and sustainable development. Landscape Ecol 24:1037-1052

Verburg PH, Crossman N, Ellis EC et al (2015) Land system science and sustainable development of the earth system: a global land project perspective. Anthropocene 12:29-41

Wang Z, Tan PY, Zhang T, Nassauer JI (2014) Perspectives on narrowing the action gap between landscape science and metropolitan governance: practice in the US and China. Landsc Urban Plan 125(Supplement C):329-334

Westerink J, Opdam P, Van Rooij S, Steingröver E (2017) Landscape services as boundary concept in landscape governance: building social capital in collaboration and adapting the landscape. Land Use Policy 60:408-418

Wu J (2013) Landscape sustainability science: ecosystem services and human well-being in changing landscapes. Landscape Ecol 28:999-1023 